\title{
Is Helicobacter pylori Infection Associated with Perforated Gastro-Duodenal Ulcer?
}

\author{
K. Thirupathaiah ${ }^{1}$, Sanjeeva Raju Kunche², Nagella Pradeep Kumar Reddy ${ }^{3}$ \\ ${ }^{1}$ Department of General Surgery, Sri Venkateshwaraa Medical College Hospital and Research Center, \\ Ariyur, Pondicherry, India. ${ }^{2}$ Department of General Surgery, Sri Venkateshwaraa Medical College \\ Hospital and Research Center, Ariyur, Pondicherry, India. ${ }^{3}$ Department of General Surgery, Sri \\ Venkateshwaraa Medical College Hospital and Research Center, Ariyur, Pondicherry, India.
}

\section{ABSTRACT}

\section{BACKGROUND}

About $95 \%$ of the patients suffering from duodenal ulcer and $70-80 \%$ of the gastric ulcer patients are found to be Helicobacter pylori (H. pylori) positive. Although the role of H. pylori is well known in peptic ulcer disease aetiology, its role in perforated peptic ulcer is not well established. There are conflicting results in the literature regarding its association, with some studies showing high prevalence of $H$. pylori infection in gastro-duodenal perforation patients and also its eradication prevented the relapse of ulcer while others showing low or lack of association, suggesting a different pathogenesis for perforated peptic ulcer.

\section{METHODS}

Group-I patients were operated for gastro-duodenal perforation and group-II patients were with the upper gastrointestinal endoscopic diagnosis of peptic ulcer disease. The mucosal biopsy samples taken from antrum from both the groups were tested with rapid urease test and histopathological examination to detect $H$. pylori.

\section{RESULTS}

The prevalence of $H$. pylori infection was significantly less in patients with perforated gastro-duodenal ulcer than with peptic ulcer disease ( $p$-value-0.026; OR $-0.31)$.

\section{CONCLUSIONS}

Through this study it was found that alcohol intake and smoking were significant risk factors associated with perforation of gastro-duodenal ulcer whereas NSAIDs use was not significantly associated. H. pylori infection was not significantly associated with perforated gastro-duodenal ulcer suggesting that some other factors were involved in perforation.

\section{KEY WORDS}

Pre-Pyloric Perforation, D1 Perforation, Alcohol and Smoking Induced Gastroduodenal Perforation, H. pylori Infection
Corresponding Author: Dr. Sanjeeva Raju Kunche, No. 202, A-Block, 2nd Floor, Sri Venkateshwaraa Medical College \& Research Centre, Ariyur-605009,

Pondicherry, India.

E-mail: sanjeev2001jipmer@yahoo.com

DOI: $10.14260 / \mathrm{jemds} / 2020 / 293$

Financial or Other Competing Interests: None.

How to Cite This Article:

Thirupathaiah K, Kunche SR, Reddy NPK. Is Helicobacter pylori infection associated with perforated gastro-duodenal ulcer? J. Evolution Med. Dent. Sci. 2020;9(16): 1345-1348, DOI: 10.14260/jemds/2020/293

Submission 11-02-2020, Peer Review 03-04-2020, Acceptance 10-04-2020, Published 20-04-2020.

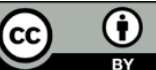




\section{BACKGROUND}

The incidence of perforated gastro-duodenal ulcer has changed minimally in spite of use of anti-secretory and Helicobacter pylori eradicative agents. In the west, epidemiology has drifted to elderly age group over the past two decades. But the male to female ratio which was $2: 1$, still persists in India. ${ }^{[1]}$ The most common reason for perforation is NSAIDs use in west.[2] Tobacco use, alcohol intake and history of peptic ulcer are known risk factors for ulcer disease complications. [3] Helicobacter pylori infection plays a major role in the pathogenesis of duodenal ulcer. There are several reports in the literature studying the prevalence of $H$. pylori in perforated peptic ulcer disease and its association. ${ }^{[4-}$ 7] Many reports showed that the ulcer recurrence was seen even after the $H$. pylori eradication, indicating other risk factors for the ulcer disease. ${ }^{[8]}$ Some reports say that $50 \%$ of acute duodenal ulcerations are $H$. pylori negative. ${ }^{[8]}$ About $95 \%$ of the patients suffering from duodenal ulcer and 70 $80 \%$ of the gastric ulcer patients are found to be Helicobacter pylori (H. pylori) positive. ${ }^{[3]}$ Although the role of H. pylori is well known in peptic ulcer disease aetiology, its role in perforated peptic ulcer is not well established.[4-9] There are conflicting results in the literature regarding its association, with some studies showing high prevalence of $H$. pylori infection in gastro-duodenal perforation patients and also its eradication prevented the relapse of ulcer while others showing low or lack of association, suggesting a different pathogenesis for perforated peptic ulcer.[3,8-9] In spite of proven evidence of long-term healing of duodenal ulcer after H. pylori eradication, it still may not be the primary cause for the ulceration.

Because of all this conflicting results and paucity of data, this study was undertaken to assess the role of H. pylori in patients with gastro-duodenal perforation. We wanted to assess the association of $H$. pylori infection in patients with perforated gastro-duodenal (peptic) ulcer and compare it with the prevalence in patients with peptic ulcer disease.

\section{METHODS}

This was an analytical cross-sectional study conducted in the Department of General Surgery, at the SVMCH \& RC Puducherry. Study was done after getting approval from the institutional ethical committee, and an informed consent was obtained from the patients. The period of study was of 17 months from July 2018 to December 2019. The group-I and the group-II patients enrolled in this study.

\section{Group-I}

All Patients above 18 years of age who were operated for gastro-duodenal perforation.

\section{Group-II}

Patients above 18 years with the upper gastrointestinal endoscopic diagnosis of peptic ulcer disease or erosive mucosal disease.
In the first group, mucosal biopsy was taken during surgery from the antrum of the stomach through the perforation using sterile endoscopic biopsy forceps. And in the second group after endoscopic diagnosis of peptic ulcer or erosive mucosal disease mucosal biopsy was taken from the antrum of the stomach.

The biopsy samples from both the groups were subjected for rapid urease test, a sample was taken which included two tissue bits in urease reagent for Rapid Urease test (RUT). In this study Pylotest TM kit manufactured and marketed by Halifax Research Laboratories, Kolkata was used for biopsy urease test $\{10\}$. Fresh mucosal biopsy from antrum was obtained with biopsy forceps and put in the urease reagent. The result was usually obtained by 6-9 h but could be interpreted up to $24 \mathrm{~h}$. However, in this study the results were obtained within 6-9 h, in majority of the cases. Rapid urease kit shows positive (pink) or negative (yellow) results and histopathological (modified Giemsa stain) examination to detect $H$. pylori. The patients were considered to have $H$. pylori infection when any one or both of the above tests were positive.

\section{Statistical Analysis}

The results of the primary outcome variables $(H$. pylori positive gastro-duodenal perforation and peptic ulcer disease) and sociodemographic and clinical variables (age grouping, gender) were presented as numbers (\%). The differences between two groups with and without $H$. pylori infection were assessed using Chi-square test and a p-value of $<0.05$ was considered significant.

\section{RESULTS}

\section{Group-I}

The highest incidence of gastro-duodenal perforation was found in the 31-40 years age group with mean age being $46.5 \pm 16$ years. It is more in male patients with a male to female ratio of 15:1. Among the total 48 patients, 22 (45.8\%) were smokers, $27(56.3 \%)$ had a history of alcohol consumption and $26(54.2 \%)$ had a history of non-steroidal anti-inflammatory drugs (NSAIDs) use. The prevalence of $H$. pylori infection among patients with perforated gastroduodenal ulcer was $6(12.5 \%)$. Out of 48 patients, $42(87.5 \%)$ had pre-pyloric perforation and $6(12.5 \%)$ had perforation in the first part of duodenum.

\section{Group-II}

Of the total 48 patients, 38 were male and 10 were female, with a ratio of 3.8:1. The highest incidence of peptic ulcer or erosive mucosal disease was found in the 51-60 years age group with a mean age of $47.3 \pm 13$ years. Among them, 8 $(16.7 \%)$ had a history of smoking, $12(25 \%)$ had history of alcohol consumption and $24(50 \%)$ had history of NSAIDs use. Out of these 48 patients, 14 had antral gastritis, 14 had duodenitis, 16 had pangastritis and 4 had pre-pyloric ulcer. $H$. pylori was detected in 15 (31.25\%) patients. 
The prevalence of $H$. pylori infection was significantly less in patients with perforated gastro-duodenal ulcer than with peptic ulcer disease (p-value-0.026; OR - 0.31). There exists a statistical difference between Group-I and Group-II when alcohol intake and smoking were considered as positive risk factors with significant $p$ value of 0.002 for both and an Odds ratio of more than one ( 3.85 and 4.23 respectively).

\begin{tabular}{|c|c|c|c|}
\hline Parameter & $\begin{array}{l}\text { Group-I } \\
(n=48)\end{array}$ & $\begin{array}{c}\text { Group-II } \\
(n=48)\end{array}$ & $\begin{array}{c}\text { Statistical } \\
\text { Significance }\end{array}$ \\
\hline Mean age (years) & $46.5+/-16$ & $47.3+/-13$ & \\
\hline Sex (male: female) & $15: 1$ & $3.8: 1$ & \\
\hline Smoking & $22(45.8 \%)$ & $8(16.7 \%)$ & p- 0.002 ; odds ratio- 4.23 \\
\hline Alcohol intake & $27(56.3 \%)$ & $12(25 \%)$ & p- 0.002 ; odds ratio- 3.85 \\
\hline NSAID intake & $26(54.2 \%)$ & $24(50 \%)$ & $\mathrm{p}-0.68$; odds ratio- 1.18 \\
\hline H. pylori positive & $6(12.5 \%)$ & $15(31.25 \%)$ & p- 0.026 ; odds ratio- 0.31 \\
\hline
\end{tabular}

\section{DISCUSSION}

Even though the chronicity and recurrence of peptic ulcer is strongly associated with $H$. pylori infection as shown in many studies, does it really mean that the infection should be associated with the perforated peptic ulcer also? The present study was carried out to study the association of $H$. pylori infection with gastro-duodenal ulcer perforation.

In this study, the majority of the patients with perforated gastro-duodenal ulcer were in the 31-40-year age group, with a mean age of $46.5 \pm 16.0$ years. Predominantly males were affected more with a male to female ratio of $15: 1$. This was similar to a study done by Ugochukwu AI et al and Dogra B et al where males were most commonly affected with a ratio of 3.2:1 and 3:1 respectively. [11,12] Also the mean ages of presentation in both these studies were $39.5 \pm 13$ years and 49.2 years respectively. In another study done by John B P et $\mathrm{al}$, they found that the mean age to be of $52.81 \pm 14.5$ years, with a male to female ratio of 4.14:1. [13] In the present study, majority of the peptic ulcer disease patients belonged to 40 60 years age group with the mean age of $47.3 \pm 13$ years and a male to female ratio of 3.8:1.

The present study shows that the prevalence of $H$. pylori infection among patients presenting with a perforated gastroduodenal ulcer was 12.5\%. Among them 87.5\% had perforation in the pre-pyloric region and $12.5 \%$ was in the first part of duodenum. The prevalence of $H$. pylori infection among patients with peptic ulcer disease was 31.3\%. Among them $91.7 \%$ had erosive mucosal disease and $8.3 \%$ had peptic ulcer disease? This was based on the rapid urease test and histopathological examination. The results were statistically significant with a p value of 0.026 when $H$. pylori is considered as an exposure factor and with odds ratio of 0.31 , we found that $H$. pylori infection was not significantly associated with perforated gastro-duodenal ulcer. This is similar to the study done by Reinbach et al in which the prevalence of $H$. pylori infection in perforated duodenal ulcer was Parameter Group I $(n=48)$ Group II $(n=48)$ Statistical significance Mean Age (years) 46.5 \pm 16 47.3 \pm 13 Sex (Male: Female) 15:1 3.8:1 Smoking 22 (45.8\%) 8 (16.7\%) p-0.002; odds ratio-4.23 Alcohol intake 27 (56.3\%) 12 (25\%) p-0.002; odds ratio 3.85 NSAID intake 26 (54.2\%) 24 (50\%) p-0.68; odds ratio-1.18 H. pylori positive 6 (12.5\%) 15 (31.25\%) p0.026; odds ratio-0.31 significantly less with an infection rate of $47 \%{ }^{[8]}$ They found that chronic recurrent peptic ulcer disease and perforated gastro-duodenal ulcer has a different pathogenesis based on the fact that there is low prevalence of $H$. pylori infection in patients presented with perforated gastro-duodenal ulcer. It also suggests that other pathogenic factors might play a role in perforated gastro-duodenal ulcer. Also, another study done by Chowdhary SK et al found that all their 15 patients with perforated duodenal ulcer were negative for $H$. pylori.[14] But in contrary to our study, most other studies showed a significant association of $H$. pylori infection with perforated peptic ulcer as shown in the following table. The discrepancy in the infection rates found in the literature may be attributed in part to the different populations studied.

\begin{tabular}{|c|c|c|c|}
\hline Author & Year & $\begin{array}{l}\text { Prevalence of } H \text {. pylori Infection } \\
\text { in Perforated Peptic Ulcer }\end{array}$ & Result \\
\hline Sebastian ${ }^{(15)}$ & 2001 & $83.3 \%$ & Significant \\
\hline Metzger( ${ }^{(3)}$ & 2001 & $73 \%$ & Significant \\
\hline $\operatorname{Metzger}^{(3)}$ & 2001 & $73 \%$ & Significant \\
\hline Ugochukwu ${ }^{(11)}$ & 2013 & $65-70 \%$ & Significant \\
\hline $\operatorname{Dogra}^{(12)}$ & 2014 & $92 \%$ & Significant \\
\hline John BP(13) & 2017 & $47 \%$ & Significant \\
\hline
\end{tabular}

In the present study, $45.8 \%$ patients in group I were smokers, among which $13.63 \%$ were tested positive for $H$. pylori. Also in group II, only $16.66 \%$ were smokers, of which only one patient was tested positive for $H$. pylori infection. Alcohol intake is another attributable risk factor for perforated gastro-duodenal ulcer. In the present study $56.3 \%$ of perforated gastro-duodenal ulcer patients had a history of alcohol intake and among them two were tested positive for H. pylori. In peptic ulcer disease patients, $25 \%$ had a history of alcohol consumption of which 5 were found to be positive for $H$. pylori. The results were statistically significant ( $p$ 0.002) when alcohol intake and smoking were considered as risk factors for perforated peptic ulcer disease. Based on odds ratio ( 3.85 and 4.23 respectively), it was found that both alcohol intake and smoking were risk factors for perforated gastro-duodenal ulcer. This was similar to a study done by Ugochukwu et al who showed that smoking and alcohol consumption was significantly associated with perforation in young men of developing countries.[10]

\section{CONCLUSIONS}

Through this study it was found that alcohol intake and smoking were significant risk factors associated with perforation of gastro-duodenal ulcer $(\mathrm{p}=0.002$ and $\mathrm{p}=0.002$ respectively) whereas NSAIDs use was not significantly associated $(\mathrm{p}=0.083)$. With a $\mathrm{p}$ value of 0.026 and odds ratio of $0.31, H$. pylori infections was not significantly associated with perforated gastro-duodenal ulcer suggesting that some other factors were involved in perforation. Also, the H. pylori eradication therapy $\mathrm{m}$ may not be helpful to prevent 
recurrent ulcer in all patients treated for peptic ulcer perforation.

\section{REFERENCES}

[1] Shankar LJ, Channadasar S. Risk factors and seasonal trends of duodenal ulcer perforation. Int Surg J 2016;3 (2):876-8.

[2] Williams N, O'Connell PR. Bailey \& Love's Short Practice of Surgery. 26 $6^{\text {th }}$ edn. CRC Press 2013.

[3] Metzger J, Styger S, Sieber C, et al. Prevalence of Helicobacter pylori infection in peptic ulcer perforations. Swiss Med Wkly 2001;131 (7-8):99-103.

[4] Sharma AK, Mittal S, Malvi SK. Association of Helicobacter pylori with peptic perforation in Chhattisgarh region of India. Trop Gastroenterol 2000;21 (1):42-3.

[5] Ng EK, Lam YH, Sung JJ, et al. Eradication of Helicobacter pylori prevents recurrence of ulcer after simple closure of duodenal ulcer perforation: randomized controlled trial. Ann Surg 2000;231 (2):153-8.

[6] Chu KM, Kwok KF, Law SY, et al. Helicobacter pylori status and endoscopy follow-up of patients having a history of perforated duodenal ulcer. Gastrointest Endosc 1999;50 (1):58-62.
[7] Mihmalni M, Isgor A, Kabukcuoglu F, et al. The effect of Helicobacter pylori in perforation of duodenal ulcer. Hepatogastroenterology 1998;45 (23):1610-2.

[8] Reinbach DH, Cruickshank G, McColl KE. Acute perforated duodenal ulcer is not associated with Helicobacter pylori infection. Gut 1993;34 (10):1344-7.

[9] Hobsley M, Tovey FI, Holton J. Precise role of $H$. pylori in duodenal ulceration. World J Gastroenterol WJG 2006;12 (40):6413-9.

[10] Roy AD, Deuri S, Dutta UC. The diagnostic accuracy of rapid urease biopsy test compared to histopathology in implementing "test and treat" policy for Helicobacter pylori. Int J Appl Basic Med Res 2016;6 (1):18-22.

[11] Ugochukwu AI, Amu OC, Nzegwu MA, et al. Acute perforated peptic ulcer: on clinical experience in an urban tertiary hospital in south east Nigeria. Int J Surg 2013;11 (3):223-7.

[12] Dogra B, Panchabhai S, Rejinthal S, et al. Helicobacter pylori in gastroduodenal perforation. Med J Dr. Patil Univ 2014;7 (2):170-2.

[13] John B, Mathew BP, Chandran CV. Prevalence of Helicobacter pylori in peptic ulcer perforation. Int Surg J 2017;4 (10):3350-3.

[14] Chowdhary SK, Bhasin DK, Panigrahi D, et al. Helicobacter pylori infection in patients with perforated duodenal ulcer. Trop Gastroenterol 1998;19 (1):19-21.

[15] Sebastian M, Chandran VP, Elashaal YI, et al. Helicobacter pylori infection in perforated peptic ulcer disease. Br J Surg $1995 ; 82$

(3):360-2 